\title{
Pigment Epithelium-Derived Factor Declines in Response to an Oral Glucose Load and Is Correlated with Vitamin D and BMI but Not Diabetes Status in Children and Young Adults
}

\author{
Allison C. Sylvetsky ${ }^{a-c}$ Najy T. Issa ${ }^{b}$ Avinash Chandran ${ }^{b}$ Rebecca J. Brown ${ }^{a}$ \\ Hussam J. Alamri ${ }^{a}$ Gabriella Aitcheson ${ }^{a}$ Mary Walter ${ }^{d}$ Kristina I. Rother ${ }^{a}$ \\ a Section on Pediatric Diabetes and Metabolism, NIDDK, NIH, Bethesda, MD, USA; ${ }^{b}$ Department of Exercise \\ and Nutrition Sciences, Milken Institute School of Public Health, The George Washington University, \\ Washington, DC, USA; ' Sumner M. Redstone Global Center for Prevention and Wellness, Milken Institute \\ School of Public Health, The George Washington University, Washington, DC, USA; dClinical Core Laboratory, \\ NIDDK, NIH, Bethesda, MD, USA
}

\section{Keywords \\ Diabetes · Obesity $\cdot$ Adolescents $\cdot$ Bone $\cdot$ Metabolism}

\begin{abstract}
Background: Pigment epithelium-derived factor (PEDF) is associated with obesity and diabetes complications in adults, yet little is known about PEDF in younger individuals. We investigated the relationship between PEDF and various metabolic biomarkers in young healthy volunteers (HV) and similar-aged patients with diabetes (type 1 and type 2). Methods: A fasting blood sample was collected in $48 \mathrm{HV}, 11$ patients with type 1 diabetes (T1D), and 11 patients with type 2 diabetes (T2D) 12-25 years of age. In 9 healthy subjects, PEDF was also serially measured during a frequently sampled oral glucose tolerance test (OGTT). Results: PEDF was positively correlated with BMI and systolic blood pressure and negatively correlated with vitamin D. Upon multivariable analysis, BMI and vitamin D were independent predictors of PEDF. Prior to adjustment, PEDF was highest in T2D patients $(7,168.9 \pm 4417.4 \mathrm{ng} / \mathrm{mL})$ and lowest in individuals with T1D $(2,967.7 \pm 947.1 \mathrm{ng} / \mathrm{mL})$ but did not differ by diag-
\end{abstract}

\section{KARGER}

(c) 2017 S. Karger AG, Basel

E-Mail karger@karger.com

www.karger.com/hrp nosis when adjusted for $\mathrm{BMI}$ and vitamin $\mathrm{D}$. Among volunteers who underwent an OGTT, PEDF declined by 20\% in response to an oral glucose load. Conclusion: PEDF was acutely regulated by a glucose load and was correlated with $\mathrm{BMI}$ but not with diabetes. The negative correlation with vitamin $\mathrm{D}$, independent of $\mathrm{BMI}$, raises the question whether PEDF plays a compensatory role in bone matrix mineralization.

(c) 2017 S. Karger AG, Basel

\section{Introduction}

Pigment epithelium-derived factor (PEDF) is a 50$\mathrm{kDa}$ secreted glycoprotein that belongs to the noninhibitory serpin group. It is a neurotrophic factor and a natural angiogenesis inhibitor with antitumor, anti-inflammatory, immunomodulatory, and microvascular protective properties [1]. It is widely expressed in a range of human tissues including the eyes, brain, bone, and kidneys, and is one of the most highly secreted proteins from human adipocytes [1]. Surprisingly little is known about its met- 
abolic regulation and functions, other than a close, positive relationship with adipose tissue mass $[2,3]$. For example, PEDF expression in adipocytes and circulating PEDF levels increased with the development of obesity and insulin resistance in a rodent model [4] and weight loss resulted in decreased serum PEDF in both animal models of obesity and obese human subjects $[5,6]$.

Higher PEDF concentrations have been observed in patients with diabetes relative to healthy controls, especially in those with vascular complications, compared to patients without vascular disease [7-10]. It has been hypothesized that PEDF increases in order to limit microvascular damage $[4,11-13]$. This is exemplified by retinopathy, where PEDF has been shown to exert antiangiogenic effects [14]. PEDF-mediated protection against reactive oxygen species has also been proposed [15].

While PEDF is associated with insulin resistance in adults [16], limited data are available in children. Tryggestad et al. [17] reported that PEDF concentrations were similar in obese children with and without type 2 diabetes (T2D) and higher in obese compared to normal-weight children, regardless of diabetes [17]. In a separate report by the same group, PEDF was found to be positively associated with both lean mass and fat mass in children with and without T2D [18]. Taken together, these findings suggest that obesity, rather than diabetes per se, promotes increased PEDF.

Given that cardiovascular disease disproportionately affects individuals with type 1 diabetes (T1D) [19] and that certain adipokines (e.g., adiponectin) are regulated differently in this condition, we were especially interested in investigating PEDF and biomarkers of cardiometabolic health in young individuals with T1D in comparison with youth with T2D and in healthy volunteers (HV). We also tested whether PEDF responds acutely to a metabolic challenge by conducting an oral glucose tolerance test.

\section{Methods}

Study participants were recruited through the NIH Healthy Volunteer Office. Patients with diabetes were referred by their physicians and enrolled into NCT00445627. All patients enrolled in this trial were included in the present analysis, without selection bias. They underwent detailed assessment including personal and family history, physical examination, residual insulin secretion, and antibody status. Forty-eight HV aged $18.3 \pm 4.1$ years, 11 patients with T1D aged $17.9 \pm 3.3$ years, and 11 patients with T2D aged $18.3 \pm 3.4$ years, all without overt microvascular or macrovascular complications, provided written consent prior to enrollment. Individuals under the age of 18 years and their parents (or guard- ians) also provided written assent and consent. All study procedures were reviewed and approved by the Institutional Review Board (IRB) at the National Institute of Diabetes, Digestive, and Kidney Diseases (NIDDK) at the National Institutes of Health $(\mathrm{NIH})$ and in accordance with the Declaration of Helsinki.

Subjects underwent a routine medical evaluation, which included medical history and a physical examination. Anthropometric measurements were performed, and BMI was calculated. Blood pressure was measured using standard procedures with an appropriate cuff size. A fasting blood sample was collected for determination of complete blood count, lipid profile (total cholesterol, high-density lipoprotein cholesterol, low-density lipoprotein cholesterol, and triglycerides), blood glucose, HbA1c, leptin, adiponectin, vitamin D (total 25-hydroxyvitamin D2 and D3), high-sensitivity C-reactive protein, free fatty acids, liver enzymes (alanine transaminase, aspartate transaminase), and PEDF.

PEDF was measured using a sandwich ELISA kit (sensitivity: $0.9 \mathrm{ng} / \mathrm{mL}$; range of detection: $0.9-62.5 \mathrm{ng} / \mathrm{mL}$; intra-assay variation: $\pm 5.3 \%(7.5 \mathrm{ng} / \mathrm{mL})$; inter-assay variation $\pm 16.0 \%(7.5 \mathrm{ng} / \mathrm{mL})$; CHEMICON International, Inc.). All samples were run using the same assay. Leptin was measured in serum using the Human Leptin ELISA kit from Millipore (Billerica, MA, USA). The minimum detectable concentration was $0.5 \mathrm{ng} / \mathrm{mL}$ (IntraCV: $3.7 \%$ and InterCV: $4.0 \%)$. Adiponectin was measured in serum by ELISA (Human Total Adiponectin Quantikine kit; R\&D Systems, Minneapolis, MN, USA; IntraCV: $3.5 \%$ and InterCV: $6.5 \%)$. The minimum detectable concentration was $0.25 \mathrm{ng} / \mathrm{mL}$. All other laboratory measurements were conducted using standard clinical procedures in the NIH Clinical Center Laboratory.

In a subset of subjects $(9 \mathrm{HV})$ who underwent an oral glucose tolerance test (OGTT), PEDF was measured prior to $(-10,0 \mathrm{~min})$ oral ingestion of $75 \mathrm{~g}$ glucose and then serially $(10,20,30,60,90$, 120,150 , and $180 \mathrm{~min}$ ) following the glucose load.

\section{Statistical Analysis}

Statistical analyses were performed using SAS Enterprise Guide version 9.3 for Windows (SAS Institute Inc.). All continuous data are expressed as mean \pm SD. All categorical data are reported as frequencies (\%). Univariate analyses were performed to evaluate associations between serum PEDF and metabolic biomarkers. Multivariable regression was then performed using PROC REG, with adjustment for relevant covariates. Statistical significance was defined as $p<0.05$. As this was an exploratory study, a correction for multiple comparisons was not performed.

\section{Results}

Clinical and biochemical characteristics of the study subjects are shown in Table 1 . In univariate analyses, PEDF was significantly higher in patients with T2D compared to those with T1D or HV $(7,168.9 \pm 4,417.4 \mathrm{ng} / \mathrm{mL}$ $[\mathrm{T} 2 \mathrm{D}], 2,967.7 \pm 947.1 \mathrm{ng} / \mathrm{mL}[\mathrm{T} 1 \mathrm{D}]$, and 5,229.9 \pm 2,274.7 [HV], $p=0.0015$ ) (Fig. 1).

Bivariate analyses revealed significant positive correlations of PEDF with BMI $(r=0.540, p<0.0001)$ and systolic blood pressure $(r=0.352, p=0.003)$ and a negative 
Table 1. Characteristics of the study subjects

\begin{tabular}{|c|c|c|c|c|}
\hline & $\begin{array}{l}\text { Healthy volunteers } \\
(n=48)\end{array}$ & $\begin{array}{l}\text { Type } 1 \text { DM } \\
(n=11)\end{array}$ & $\begin{array}{l}\text { Type } 2 \text { DM } \\
(n=11)\end{array}$ & $p$ \\
\hline Gender (M:F), $n$ & $24: 24$ & $4: 7$ & $2: 9$ & 0.14 \\
\hline Age, years & $18.3 \pm 4.1$ & $17.9 \pm 3.3$ & $18.3 \pm 3.4$ & 0.99 \\
\hline \multicolumn{4}{|l|}{ Race/ethnicity, \% } & \multirow[t]{4}{*}{0.37} \\
\hline White & 44 & 64 & 36 & \\
\hline Black & 39 & 9 & 36 & \\
\hline Other & 17 & 27 & 28 & \\
\hline Hispanic & 15 & 18 & 9 & 0.83 \\
\hline DM duration, years & na & $7.7 \pm 4.9$ & $1.7 \pm 1.6$ & na \\
\hline BMI & $26.3 \pm 6.5$ & $21.5 \pm 2.8$ & $35.4 \pm 6.5$ & $<0.0001$ \\
\hline Systolic BP, mm Hg & $120.9 \pm 11.9$ & $110.9 \pm 12.0$ & $127.5 \pm 8.5$ & 0.004 \\
\hline Diastolic BP, mm Hg & $68.7 \pm 7.3$ & $68.2 \pm 9.6$ & $72.6 \pm 9.2$ & 0.43 \\
\hline Pulse, beat $/ \mathrm{min}$ & $71.3 \pm 10.6$ & $79.5 \pm 11.5$ & $80.4 \pm 9.9$ & 0.01 \\
\hline ALT, U/L & $22.8 \pm 15.2$ & $16.7 \pm 3.4$ & $43.8 \pm 28.5$ & 0.0021 \\
\hline AST, U/L & $26.8 \pm 31.1$ & $22.9 \pm 8.9$ & $25.0 \pm 9.1$ & 0.64 \\
\hline $\mathrm{WBC}, \mathrm{K} / \mu \mathrm{L}$ & $5.9 \pm 1.4$ & $6.4 \pm 1.4$ & $8.0 \pm 2.2$ & 0.004 \\
\hline Total cholesterol, mg/dL & $150.3 \pm 25.9$ & $155.6 \pm 39.3$ & $171.4 \pm 40.4$ & 0.31 \\
\hline $\mathrm{HDL}-\mathrm{C}, \mathrm{mg} / \mathrm{dL}$ & $48.3 \pm 10.4$ & $55.5 \pm 15.4$ & $38.2 \pm 8.1$ & 0.0015 \\
\hline $\mathrm{LDL}, \mathrm{mg} / \mathrm{dL}$ & $91.1 \pm 27.7$ & $85.8 \pm 34.1$ & $113.5 \pm 41.3$ & 0.11 \\
\hline Triglycerides, mg/dL & $67.0 \pm 31.1$ & $68.3 \pm 42.8$ & $150.3 \pm 87.1$ & 0.0003 \\
\hline Free fatty acids, $\mu \mathrm{Eq} / \mathrm{L}$ & $582.3 \pm 235.8$ & $647.0 \pm 444.0$ & $682.1 \pm 329.2$ & 0.82 \\
\hline 25-OH-vitamin $\mathrm{D}, \mathrm{ng} / \mathrm{mL}$ & $16.6 \pm 7.8$ & $26.0 \pm 7.0$ & $15.6 \pm 9.2$ & 0.002 \\
\hline Vitamin D status, $\%$ optimal $^{\mathrm{a}}$ & 24 & 90 & 27 & 0.001 \\
\hline \multicolumn{5}{|l|}{ 1-25-OH2-vitamin $\mathrm{D}, \mathrm{pg} / \mathrm{mL}$} \\
\hline Normal range (22--67) & $50.1 \pm 14.4$ & $39.4 \pm 5.9$ & $46.8 \pm 22.1$ & 0.07 \\
\hline HbAlc, \% & $5.2 \pm 0.4$ & $7.9 \pm 1.8$ & $7.7 \pm 2.0$ & $<0.0001$ \\
\hline Glucose, mg/dL & $82.4 \pm 6.3$ & $115.7 \pm 33.1$ & $131.6 \pm 57.8$ & $<0.0001$ \\
\hline Insulin, $\mu \mathrm{U} / \mathrm{mL}$ & $7.2 \pm 5.5$ & NA & $16.0 \pm 7.9$ & 0.0004 \\
\hline C-peptide, $n g / m L$ & $1.8 \pm 0.8$ & $0.3 \pm 0.7$ & $2.9 \pm 1.1$ & $<0.0001$ \\
\hline HOMA-IR & $1.5 \pm 1.2$ & na & $4.9 \pm 3.3$ & $<0.0001$ \\
\hline Creatinine, $\mathrm{mg} / \mathrm{dL}$ & $0.79 \pm 0.15$ & $0.73 \pm 0.09$ & $0.64 \pm 0.08$ & 0.005 \\
\hline \multicolumn{5}{|l|}{ hs-CRP, mg/L } \\
\hline Normal range $(<3)$ & $1.27 \pm 2.3$ & $2.3 \pm 3.93$ & $6.87 \pm 9.1$ & 0.001 \\
\hline Leptin, $\mathrm{ng} / \mathrm{mL}$ & $26.6 \pm 24.3$ & $17.8 \pm 10$ & $45 \pm 34.9$ & 0.02 \\
\hline Adiponectin, ng/mL & $5,815.5 \pm 3,745.3$ & $7,594.4 \pm 3,006.5$ & $2,581.9 \pm 856.8$ & $<0.0001$ \\
\hline
\end{tabular}

Unless otherwise indicated, data are given as means \pm standard deviation for all continuous variables. Group differences in continuous variables were examined using Kruskal-Wallis tests ( $>2$ groups) and Wilcoxon rank sum tests ( 2 groups) for all variables, except for systolic blood pressure, pulse and $25-\mathrm{OH}$-vitamin $\mathrm{D}$, where parametric tests (ANOVA) were used. $\chi^{2}$ tests of (no) association were used to examine categorical variables. Inferences were made based on a Bonferroni-adjusted probability cutoff of $0.002(0.05 / n$ where $n=29)$. DM, diabetes mellitus; BMI, body mass index; BP, blood pressure; ALT, alanine transaminase; AST, aspartate transaminase; WBC, white blood cells; HDL-C, high-densitylipoprotein cholesterol; LDL, low-densitylipoprotein; HOMA-IR, homeostatic model assessment for insulin resistance; hs-CRP, high-sensitivity C-reactive protein. ${ }^{a}$ Optimal vitamin D status is defined as a $25(\mathrm{OH}) \mathrm{D}$ concentration $>20 \mathrm{ng} / \mathrm{mL}$. $\mathrm{p}$ values in bold indicate statistical significance $(p<0.05)$.

correlation with vitamin D $(-0.408, p=0.0006)$ when all 70 subjects were analyzed together. When analyzed separately by diagnosis, vitamin $\mathrm{D}$ was inversely correlated with PEDF only among HV, and BMI was positively correlated in both HV $(n=48)$ and in those with T2D $(n=$
11). No significant correlations between PEDF and any biomarker analyzed were observed among patients with $\mathrm{T} 1 \mathrm{D}(n=11)$.

In a multivariable linear regression model driven by the correlation matrix, only BMI $(p=0.05)$ and vitamin 


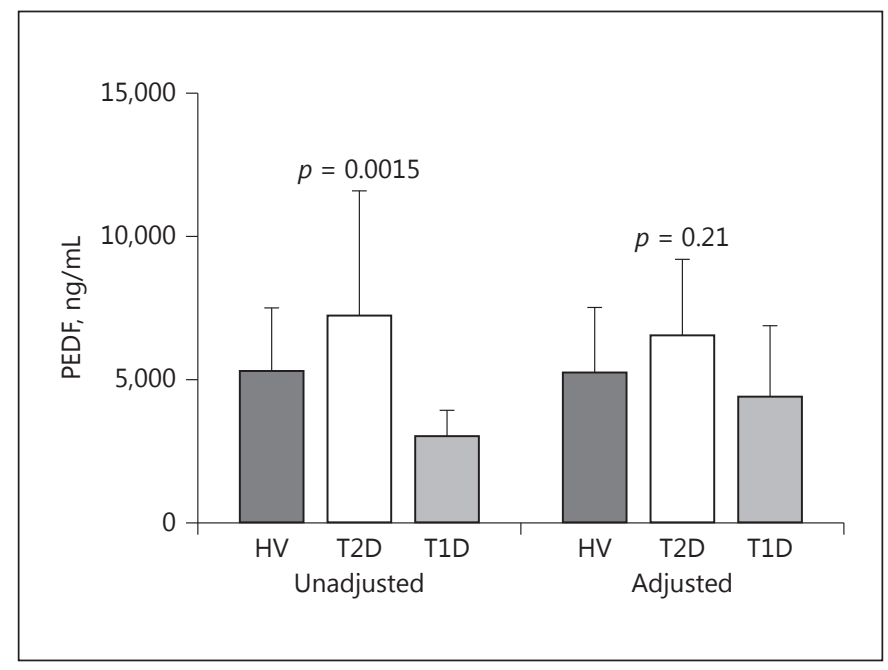

Fig. 1. Pigment epithelium-derived factor (PEDF) levels stratified by diabetes diagnosis. Fasted PEDF levels were higher in patients with type 2 diabetes (T2D) compared to those with type 1 diabetes (T1D) or healthy volunteers (HV) in unadjusted analyses, but did not differ following adjustment for BMI and vitamin D.

$\mathrm{D}(p=0.048)$ were found to be marginally significant predictors of PEDF in the pooled sample. Importantly, diagnosis was not a significant predictor of PEDF in this model $(p=0.21)$. A final reduced model was fit, in which BMI $(p<0.0001)$ and vitamin $\mathrm{D}(p=0.014)$ explained $34 \%$ of the variance in PEDF within the pooled sample $(29.3 \%$ of variance explained by BMI and $6.4 \%$ of variance explained by vitamin D). While we explored introducing other variables such as race/ethnicity and gender into the model, none were statistically significant, and thus, only BMI (parameter estimate \pm SE: $182.3 \pm 41.8, p<0.0001$ ) and vitamin $\mathrm{D}$ (parameter estimate \pm SE: $-86.5 \pm 34.2$, $p<0.014)$ were retained. Because diagnosis was not a significant predictor and due to limited sample sizes of patients with diabetes, we did not stratify this model by diagnosis for further examination.

Because vitamin $\mathrm{D}$ deficiency was prevalent in both HV and T2D patients (Table 1), we determined whether vitamin $\mathrm{D}$ remained a significant predictor when levels were "normalized" by conducting a combined analysis of HV and T1D patients. We also explored whether this relationship was maintained when vitamin D deficiency was "exacerbated", by conducting a combined analysis of $\mathrm{HV}$ and T2D patients. In both cases, BMI $(p=0.005$ in T1D and HV combined, $p=0.0004$ in T2D and HV combined) and vitamin $\mathrm{D}$ ( $p=0.032$ in T1D and HV combined, $p=0.026$ in T2D and HV combined) remained significant predictors of PEDF.

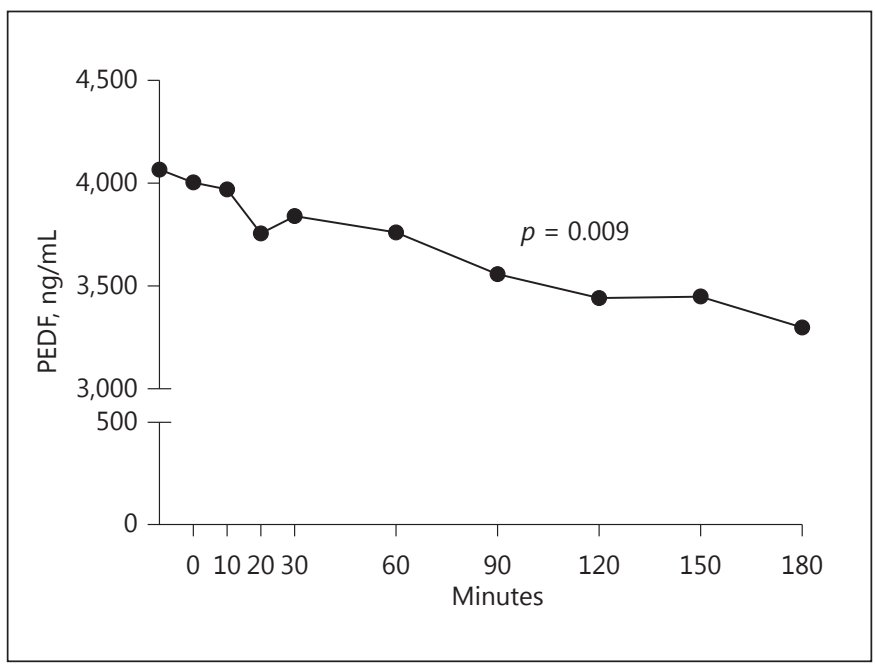

Fig. 2. Pigment epithelium-derived factor (PEDF) response to oral glucose load in 9 healthy volunteers. At 60, 120, 150 and $180 \mathrm{~min}$, PEDF levels were significantly decreased compared to baseline ( $p=0.0402, p=0.0302, p=0.0145$, and $p=0.0127$, respectively).

In the subset of $\mathrm{HV}$ with serial measurements of PEDF during an OGTT, PEDF decreased gradually following glucose ingestion relative to baseline (Fig. 2, $p=0.0009$ ).

\section{Discussion}

Our results demonstrate that PEDF concentrations are regulated acutely by an oral glucose load inducing a moderate decline and are associated with BMI and vitamin D. We observed lower PEDF concentrations in adolescents and young adults with T1D compared to HV and those with T2D, but this difference was no longer significant after adjustment for BMI. This result is consistent with prior studies in healthy children and children with T2D $[5,7,10,17,20,21]$. While some adipokines are differently regulated in T1D (e.g., disproportionately high adiponectin concentrations) [22], we did not find diseasespecific alterations of PEDF.

Several mechanisms have been proposed to explain the relationship between PEDF and BMI. A direct role of adipose tissue in its regulation has been suggested and is supported by the observation that weight loss decreased PEDF in both obese humans and in animal models of obesity $[5,6]$. In addition, animal studies demonstrate that expression of PEDF in adipocytes and serum PEDF levels are greater in obese versus lean mice [6]. Even in neonates, a positive relationship has been shown be- 
tween anthropometrics (birth weight) and cord blood PEDF [23].

A novel observation in our study was the inverse relationship between vitamin D and PEDF, which remained statistically significant after adjustment for BMI. While vitamin D was not as strong a predictor of PEDF as BMI, this observation requires further investigation, especially in light of the inverse association of vitamin $\mathrm{D}$ with numerous cardiometabolic risk factors, including insulin resistance [24] and obesity [25].

In addition, PEDF may play a compensatory role to maintain bone health. Osteoblasts, and, to a lesser extent, osteoclasts express PEDF, and thus, the inverse correlation between PEDF and vitamin D may be mediated by bone matrix activity [26]. PEDF is known to inhibit adipogenesis and promote osteogenesis in mesenchymal stem cells, as PEDF knockout mice demonstrate increased adiposity and decreased bone mineral density [27]. Mutations in the gene encoding PEDF (SERPINF1) have been identified in autosomal recessive osteogenesis imperfecta type VI [28] and familial osteosclerosis [29]. Affected patients have not been described to have overt metabolic abnormalities, but no detailed studies are available. Several other adipokines have been investigated for their roles in bone metabolism. For example, leptin has been found to have no [30] or a positive [31] association with bone mineralization in adolescents. In contrast, higher adiponectin was associated with lower bone mass before and during puberty [31]. However, study results vary considerably and the significance of these interactions remains to be clarified.

The observed relationship between vitamin $\mathrm{D}$ and PEDF should be interpreted with caution, as vitamin D deficiency was prevalent among the HV and patients with T2D in our study. In addition, correlations were assessed within a small sample size of individuals with diabetes. It is also noteworthy that our HV were of a wide range of body mass indices and many were overweight $(n=14)$ or obese $(n=11)$. However, vitamin $\mathrm{D}$ deficiency is highly prevalent in the general population [32], and thus, the correlation observed in this sample may be in fact generalizable. We thus speculate that PEDF may have increased in response to low vitamin $\mathrm{D}$ concentrations.

In addition to our cross-sectional analysis, we also demonstrated that PEDF declined moderately $(\sim 20 \%)$ following ingestion of a glucose load during an OGTT. Similar effects were observed in cultured human umbilical vein endothelial cells, during which exposure to high glucose media resulted in a decreased PEDF release [33]. In humans, however, data have been mixed regarding a relationship between PEDF and fasting glucose, with some studies showing a positive correlation $[5,9,34]$, while others have not $[3,5]$. The observed gradual glucose-stimulated decline in PEDF is consistent with most other adipokines, which either remain stable or respond nondramatically to a glucose load (e.g., leptin, resistin, or omentin) [35].

In conclusion, our study is the first to compare PEDF specifically in young individuals with T1D or T2D, as well as similar-aged HV, before and after adjustment for BMI and vitamin D. These results support a link between adipose tissue and bone physiology that requires further experiments to investigate the underlying mechanisms and clinical implications.

\section{Acknowledgements}

This work was supported in part by the intramural research program of the National Institute of Diabetes and Digestive and Kidney Diseases.

\section{Disclosure Statement}

The authors have no conflicts of interest to declare.

\section{References}

1 Famulla S, Lamers D, Hartwig S, Passlack W, Horrighs A, Cramer A, Lehr S, Sell H, Eckel J: Pigment epithelium-derived factor (PEDF) is one of the most abundant proteins secreted by human adipocytes and induces insulin resistance and inflammatory signaling in muscle and fat cells. Int J Obes (Lond) 2011;35:762-772.

2 Wang P, Smit E, Brouwers MC, Goossens GH, van der Kallen CJ, van Greevenbroek MM, Mariman EC: Plasma pigment epithelium-derived factor is positively associated with obesity in Caucasian subjects, in particular with the visceral fat depot. Eur J Endocrinol 2008;159:713-718.

3 Nakamura K, Yamagishi S, Adachi H, KuritaNakamura Y, Matsui T, Inoue H: Serum levels of pigment epithelium-derived factor (PEDF) are positively associated with visceral adiposity in Japanese patients with type 2 diabetes. Diabetes Metab Res Rev 2009;25:52-56.

-4 Matsui T, Nishino Y, Ojima A, Maeda S, Tahara N, Yamagishi S: Pigment epithelium- derived factor improves metabolic derangements and ameliorates dysregulation of adipocytokines in obese type 2 diabetic rats. Am J Pathol 2014;184:1094-1103.

-5 Sabater M, Moreno-Navarrete JM, Ortega FJ, Pardo G, Salvador J, Ricart W, Fruhbeck G, Fernandez-Real JM: Circulating pigment epithelium-derived factor levels are associated with insulin resistance and decrease after weight loss. J Clin Endocrinol Metab 2010;95: $4720-4728$. 
6 Crowe S, Wu LE, Economou C, Turpin SM, Matzaris M, Hoehn KL, Hevener AL, James DE, Duh EJ, Watt MJ: Pigment epitheliumderived factor contributes to insulin resistance in obesity. Cell Metab 2009;10:40-47.

-7 Jenkins AJ, Zhang SX, Rowley KG, Karschimkus CS, Nelson CL, Chung JS, O’Neal DN, Januszewski AS, Croft KD, Mori TA, Dragicevic G, Harper CA, Best JD, Lyons TJ, Ma JX: Increased serum pigment epithelium-derived factor is associated with microvascular complications, vascular stiffness and inflammation in type 1 diabetes. Diabet Med 2007;24: 1345-1351.

-8 Katakami N, Kaneto H, Yamasaki Y, Matsuhisa M: Increased serum pigment epithelium-derived factor levels in type 1 diabetic patients with diabetic retinopathy. Diabetes Res Clin Pract 2008;81:e4-e7.

9 Chen HB, Jia WP, Lu JX, Bao YQ, Li Q, Lu FD, Lu W, Yu HY, Xiang KS: Change and significance of serum pigment epithelium-derived factor in type 2 diabetic nephropathy (in Chinese). Zhonghua Yi Xue Za Zhi 2007;87: 1230-1233.

10 Jenkins A, Zhang SX, Gosmanova A, Aston C, Dashti A, Baker MZ, Lyons T, Ma JX: Increased serum pigment epithelium derived factor levels in type 2 diabetes patients. Diabetes Res Clin Pract 2008;82:e5-e7.

-11 Haribalaganesh R, Sheikpranbabu S, Elayappan B, Venkataraman D, Gurunathan S: Pigment epithelium-derived factor down regulates hyperglycemia-induced apoptosis via pi3k/akt activation in goat retinal pericytes. Angiogenesis 2009;12:381-389.

12 Wang JJ, Zhang SX, Mott R, Knapp RR, Cao W, Lau K, Ma JX: Salutary effect of pigment epithelium-derived factor in diabetic nephropathy: evidence for antifibrogenic activities. Diabetes 2006;55:1678-1685.

$\checkmark 13$ Awad AS, You H, Gao T, Gvritishvili A, Cooper TK, Tombran-Tink J: Delayed treatment with a small pigment epithelium derived factor (PEDF) peptide prevents the progression of diabetic renal injury. PLoS One 2015;10:e133777.

14 Zang J, Guan G: Study of pigment epitheliumderived factor in pathogenesis of diabetic retinopathy. Eye Sci 2015;30:81-88.

15 Elahy M, Baindur-Hudson S, Cruzat VF, Newsholme P, Dass CR: Mechanisms of PEDF-mediated protection against reactive oxygen species damage in diabetic retinopathy and neuropathy. $J$ Endocrinol 2014;222:R129-R139.
16 Jenkins AJ, Fu D, Azar M, Stoner JA, Kaufman DG, Zhang S, Klein RL, Lopes-Virella MF, Ma JX, Lyons TJ; VADT Investigators: Clinical correlates of serum pigment epithelium-derived factor in type 2 diabetes patients. J Diabetes Complications 2014;28:353-359.

17 Tryggestad JB, Wang JJ, Zhang SX, Thompson DM, Short KR: Elevated plasma pigment epithelium-derived factor in children with type 2 diabetes mellitus is attributable to obesity. Pediatr Diabetes 2015;16:600-605.

18 Sunderland KL, Tryggestad JB, Wang JJ, Teague AM, Pratt LV, Zhang SX, Thompson DM, Short KR: Pigment epithelium-derived factor (PEDF) varies with body composition and insulin resistance in healthy young people. J Clin Endocrinol Metab 2012;97:E2114E2118.

19 Lee SI, Patel M, Jones CM, Narendran P: Cardiovascular disease and type 1 diabetes: Prevalence, prediction and management in an ageing population. Ther Adv Chronic Dis 2015;6: 347-374.

20 Yamagishi S, Adachi H, Abe A, Yashiro T, Enomoto M, Furuki K, Hino A, Jinnouchi Y, Takenaka K, Matsui T, Nakamura K, Imaizumi T: Elevated serum levels of pigment epithelium-derived factor in the metabolic syndrome. J Clin Endocrinol Metab 2006;91: 2447-2450.

21 Umei H, Yamagishi SI, Imaizumi T: Positive association of serum levels of pigment epithelium-derived factor with high-sensitivity Creactive protein in apparently healthy unmedicated subjects. J Int Med Res 2010;38: 443-448.

22 Redondo MJ, Rodriguez LM, Haymond MW, Hampe CS, Smith EO, Balasubramanyam A, Devaraj S: Serum adiposity-induced biomarkers in obese and lean children with recently diagnosed autoimmune type 1 diabetes. Pediatr Diabetes 2014;15:543-549.

23 Teague AM, Fields DA, Aston CE, Short KR, Lyons TJ, Chernausek SD: Cord blood adipokines, neonatal anthropometrics and postnatal growth in offspring of hispanic and native American women with diabetes mellitus. Reprod Biol Endocrinol 2015;13:68.

24 Chiu KC, Chu A, Go VL, Saad MF: Hypovitaminosis $\mathrm{D}$ is associated with insulin resistance and beta cell dysfunction. Am J Clin Nutr 2004;79:820-825.
25 Tzotzas T, Papadopoulou FG, Tziomalos K, Karras S, Gastaris K, Perros P, Krassas GE: Rising serum 25-hydroxy-vitamin D levels after weight loss in obese women correlate with improvement in insulin resistance. J Clin Endocrinol Metab 2010;95:4251-4257.

26 Broadhead ML, Akiyama T, Choong PF, Dass CR: The pathophysiological role of PEDF in bone diseases. Curr Mol Med 2010;10:296301.

27 Gattu AK, Swenson ES, Iwakiri Y, Samuel VT, Troiano N, Berry R, Church CD, Rodeheffer MS, Carpenter TO, Chung C: Determination of mesenchymal stem cell fate by pigment epithelium-derived factor (PEDF) results in increased adiposity and reduced bone mineral content. FASEB J 2013;27:4384-4394.

28 Homan EP, Rauch F, Grafe I, Lietman C, Doll JA, Dawson B, Bertin T, Napierala D, Morello R, Gibbs R, White L, Miki R, Cohn DH, Crawford S, Travers R, Glorieux FH, Lee B: Mutations in SERPINF1 cause osteogenesis imperfecta type VI. J Bone Miner Res 2011;26:27982803.

29 Ziff JL, Crompton M, Powell HR, Lavy JA, Aldren CP, Steel KP, Saeed SR, Dawson SJ: Mutations and altered expression of SERPINF1 in patients with familial otosclerosis. Hum Mol Genet 2016;25:2393-2403.

-30 Roemmich JN, Clark PA, Mantzoros CS, Gurgol CM, Weltman A, Rogol AD: Relationship of leptin to bone mineralization in children and adolescents. J Clin Endocrinol Metab 2003;88:599-604

31 Vishnevskaya M, Solntsava A: Bone mineral density in obese children. Pediatr Res 2011;70: 402.

32 Forrest KY, Stuhldreher WL: Prevalence and correlates of vitamin D deficiency in US adults. Nutr Res 2011;31:48-54.

33 Chen H, Jia W, Xu X, Fan Y, Zhu D, Wu H, Xie Z, Zheng Z: Upregulation of PEDF expression by PARP inhibition contributes to the decrease in hyperglycemia-induced apoptosis in HUVECs. Biochem Biophys Res Commun 2008;369:718-724.

34 Chen C, Tso AW, Law LS, Cheung BM, Ong KL, Wat NM, Janus ED, Xu A, Lam KS: Plasma level of pigment epithelium-derived factor is independently associated with the development of the metabolic syndrome in Chinese men: a 10-year prospective study. J Clin Endocrinol Metab 2010;95:5074-5081.

- 35 Cakir M, Sari R, Tosun O, Karayalcin U: Leptin response to oral glucose tolerance test in obese and nonobese premenopausal women. Endocr Res 2005;31:1-8. 